\title{
An Efficient Fault Locating Technique with Backup Protection Scheme Using Wide Area Measurement for Power System with Simultaneous Faults
}

\author{
Saptarshi ROY ${ }^{1}$, P Suresh BABU ${ }^{2}$, N V Phanendra BABU ${ }^{3}$, and Abhishek KUMAR ${ }^{4}$ \\ ${ }^{1,3}$ Research Scholar, Dept., of Electrical Engineering, NIT Warangal, INDIA \\ ${ }^{2}$ Assistant Professor, Dept., of Electrical Engineering, NIT Warangal, INDIA \\ ${ }^{4}$ M.Tech Student, Dept., of Electrical Engineering, NIT Warangal, INDIA \\ saptarshi.roy.ju@gmail.com ${ }^{1}$, phanendra229@gmail.com ${ }^{3}$ drsureshperli@nitw.ac.in
}

kabhishek1@student.nitw.ac.in

\begin{abstract}
This paper presents a synchronized phasor measurement-based wide-area backup protection scheme which uses the magnitude of sequence voltages of buses at a system protection centre to identify the faulted bus closest to the fault and faulted line. The technique is tested for various faults including simultaneous faults in various systems with interconnections. The scheme is found to be accurate and fast with today's synchronized measurement technology. Analysis using simultaneous faults is a novel contribution in this paper. It is expected that this scheme will reduce the number of disastrous blackouts and improve the reliability and security of the power system. The required information is able to distinguish between balanced and unbalanced fault in the system. The study of new back up protection scheme is done on a WSCC-3 machine-9 bus system and an IEEE 14 bus test system. The data is simulated through EMTDC/PSCAD and MATLAB /SIMULINK softwares.
\end{abstract}

Index Terms: Simultaneous Faults, Faulted bus Identification, Backup protection, faulted Line identification, Sequence Components.

Nomenclature

$\Phi_{1 s}, \Phi_{1 s}{ }^{1}$ - Phase angle between positive sequence current and Voltage before and after series capacitor.

$\Phi_{2 s}, \Phi_{2 s}{ }^{1}-$ Phase angle between negative sequence current and Voltage before and after series capacitor.

$\Phi_{1 R} \quad$ - Phase angle between positive- Sequence current and voltage at the other end of the protected line.

$\Phi_{2 R} \quad$ - Phase angle between negative- Sequence current and voltage at the other end of the protected line

$$
\begin{aligned}
& g_{1 s}=\cos \Phi_{1 s} \quad g_{1 s}{ }^{1}=\cos \Phi_{1 s}{ }^{1} \quad g_{1 R}=\cos \Phi_{1 R} \\
& g_{2 s}=\cos \Phi_{2 s} \quad g_{2 s}{ }^{1}=\cos \Phi_{2 s}{ }^{1} \quad g_{2 R}=\cos \Phi_{2 R}
\end{aligned}
$$

\section{Introduction}

In modern societies, power systems are wide spread and electric grids are more interconnected, and transmission lines are utilized close to their limits. Hence, the traditional backup protection systems can misoperate when the power system is under stress. Like the incident of the undesired operation of the third zone of distance relays can lead to cascading failure and even major power system blackouts. Therefore, there is a growing need for novel backup protection schemes to improve power system security and reliability.

Conventional backup protection schemes for the power system uses local measurements which find difficulty in distinguishing the fault from heavy loading conditions [1]. 
Maloperation of back up protection during stressed conditions causes the cascaded tripping. Wide area interconnection leads to huge number of blackouts throughout the world. Recent advancement in technology draws significant attention for the utilization of the PMU-based wide-area measurement system (WAM) for power system protection [2], [3]. Emergence of new technologies like smart electric grid increased the safety and reliability power networks and mitigates the more serious consequences like blackouts.

The wide-area backup protection (WABP) based on faulted line identification (FLI) is an interesting topic of research in recent days. This technique overcomes the limitations of conventional backup protection and allows faster remedial action since it does not need coordination among different zones. Various WABP schemes for FLI are reported [4]-[8]. In [4], a WABP is proposed that compares the positive-sequence voltage magnitude at each bus during the fault to identify the bus closest to the fault. Positive-sequence current angles of all lines connecting the selected bus are used to identify the faulted line. The residual vector of a synchrophasor-based state estimator, used in a supervisory system, is proposed in [5] to improve security of an existing remote backup protection scheme. A supervisory and an agentbased ad-hoc backup relay protection scheme based on a network infrastructure and communication are proposed in [6].

A WABP based on the fault steady-state component of voltages and currents is proposed for FLI in [7]. In the method, subsets of buses, called protection correlation regions (PCRs), are formed on the basis of network topology and PMU placement. The steady-state component of differential currents in each PCR is used to identify the PCR with the fault. A WABP algorithm based on the fault component voltage distribution is proposed in[8]. In this scheme, the fault component of voltage at one terminal of the line is estimated by utilizing the measured values of fault component voltage and current at other terminals, and the faulted line is identified based on the ratio of estimated values to measured values. A faulted area detection technique is also used to accelerate the line identification task. The integration of a series capacitor and its overvoltage protective device (metal-oxide varistor (MOV) and/or air gap) into the line introduces problems to distance relaying based transmission-line protection. Typical problems associated with relays have been addressed in [9]-[10] which include such phenomena as voltage/current inversion, sub harmonic oscillations, and additional transients caused by the air-gap operation. Performances of available WABP schemes [4]-[8] have not been evaluated for series-compensated lines and may find limitation for such lines. The problems of traditional backup protection relays can be overcome by using novel backup protection schemes, which uses phasor measurements obtained from WAMS.

This paper proposes a WABP scheme that utilizes angle information between voltage and current at both ends of a line for FLI. The scheme is accurate for the compensated and uncompensated line as evident from the evaluation for a $400-\mathrm{kV}$, 9-bus system and $138 \mathrm{KV}$ IEEE 14bus system with simultaneous faults also. The main contribution of this paper is the analysis using simultaneous faults. Previously many researcher has worked with backup protection schemes but here the analysis is done using simultaneous faults in different buses and simultaneous faults at different lengths of same line, which is totally a new idea introduced here.

\section{Phasors of Nominal Frequency Signals with Wide Area Synchrophasor System}

Consider a constant input signal $\mathrm{x}(\mathrm{t})$, with nominal frequency $\mathrm{f}_{0}$ [5].The phasor estimation at nominal frequency of the signal is estimated as follows:

$$
X(t)=X_{m} \cos \left(2 \Pi f_{0} t+\phi\right)
$$

The $\mathrm{N}$ data samples of this input $\mathrm{X}_{\mathrm{n}}:\{\mathrm{n}=0,1,2, \ldots, \mathrm{N}-1\}$ are

$$
\begin{aligned}
& X_{n}=X_{m} \cos (n \Phi+\delta) \\
& X_{c}^{n-1}=\frac{\sqrt{2}}{N} \sum_{n=0}^{N-1} X_{n} \cos (n \Phi+\delta)
\end{aligned}
$$




$$
\begin{aligned}
& =\frac{\sqrt{2}}{N} \sum_{n=0}^{N-1} X_{m} \cos (n \Phi+\delta) \cdot \cos (n \Phi) \\
& =\frac{\sqrt{2}}{N} X_{m} \sum_{n=0}^{N-1}\left[\cos \delta \cdot \cos ^{2} n \Phi-\frac{1}{2} \sin \delta \cdot \sin (2 n \Phi)\right] \\
& =\frac{X_{m}}{\sqrt{2}} \cos \delta
\end{aligned}
$$

Similarly, $X_{s}^{n-1}=\frac{\sqrt{2}}{N} \sum_{n=0}^{N-1} X_{n} \sin (n \delta)$

$$
=-\frac{X_{m}}{\sqrt{2}} \sin \delta
$$

The Phasor $X^{N-1}=X_{C}^{n-1}-j X_{s}^{n-1}$

$$
\begin{aligned}
& =\frac{X_{m}}{\sqrt{2}}[\cos \delta+j \sin \delta] \\
& =\frac{X_{m}}{\sqrt{2}} e^{j \delta}
\end{aligned}
$$

A synchrophasor system composed of Phasor measurement unit (PMU), phasor data concentrator (PDC), GPS satellite system, super PDC. The PMU collects the real time data from the various remote areas and send over it to local data concentrator called phasor data concentrator via communication system. This system serves as the backup protection system for WAPS and it is capable of acting as the substitution of conventional backup protection in power system[11,12]. The relay takes the decision is based on collected data through communication network. The suggested technique increases the reliability and stability of the system. PMU measures positive sequence voltage magnitude and current phase angle of a power system in real time with synchronised time stamped data[12]. The synchronization is done by sampling of voltage and current waveforms using timing signals from different common time reference frame, such as the Global Positioning System (GPS) Satellite or any other reference timing signal generator.

\section{A. Calculation of Protection criterion values}

Assume a voltage or current having orthogonal components $X_{1 \mathrm{c}}$ and $X_{1 \mathrm{~s}}[12,19]$.

Signal $X_{1}(n)=X_{1 c}+j X_{1 s}$

$$
\begin{aligned}
& X_{1}(n) * X_{1}(n)^{*}=X_{1 m}{ }^{2}=X_{1 c}{ }^{2}+X_{1 s}^{2} \\
& X_{1 m}=\sqrt{\left(X_{1 c}{ }^{2}+X_{1 s}^{2}\right)}
\end{aligned}
$$

B. Calculation of Power

Suppose Voltage signal is denoted by $U_{1 n}=U_{1 c}+j U_{1 s}$

Current Signal is denoted by $i_{1 n}=i_{1 c}+j i_{1 s}$

So, Power $S=U_{1 n} x i_{1 n}$

$$
\begin{aligned}
& =\left(U_{1 c}+j U_{1 s}\right) x\left(i_{1 c}-j i_{1 s}\right) \\
& =\left(U_{1 c} x i_{1 c}+U_{1 s} x i_{1 s}\right)+j\left(U_{1 s} x i_{1 c}-U_{1 c} x i_{1 s}\right)
\end{aligned}
$$

Active Power $P=0.5\left(U_{1 C} x i_{1 c}+U_{1 s} x i_{1 s}\right)$

Reactive Power $Q=0.5\left(U_{1 S} x i_{1 c}-U_{1 c} * i_{1 s}\right)$ 


\section{Proposed Method}

The proposed technique is useful for monitoring of large power networks like generating plants, large transmission lines and significant control points. Synchrophasor using phasor measurement unit provides all significant state measurement required for the operation including voltage magnitude, voltage phase angle and frequency.The rate of data sampling is maintained at $4 \mathrm{kHz}$. The Proposed Technique is follows:

\section{Algorithm:}

Step 1: Start

Step 2: Collect all data from all PMUs and PDCs in real time.

Step 3: Obtain minimum Positive sequence voltage magnitude or maximum negative or zero sequence magnitude. $\left(\mathrm{v}_{\mathrm{k}}\right)$

Step 4: Compare with the threshold value. If it is less than minimum positive sequence voltage magnitude or more than maximum negative or zero sequence magnitude value, then there is no fault in the system.

Otherwise, area or bus $\mathrm{k}$ is the nearest to the fault .

go to Step 5 and Proceed:

Step 5: Check whether it is a balanced fault or unbalanced fault.

The negative- and zero-sequence voltages are utilized to identify unbalanced faults [13]. For these faults, the pickup criterion is defined as

$$
V_{m 2} \geq K_{2} V_{n} \cup V_{m 0} \geq K_{0} V_{n}
$$

Where $\mathrm{V}_{\mathrm{m} 2} \& \mathrm{~V}_{\mathrm{m} 0}$ are the negative and Zero sequence components of the waveform of $\mathrm{m}^{\text {th }}$ bus and $\mathrm{V}_{\mathrm{n}}$ is the rated voltage of the bus. $\mathrm{K}_{2}$ and $\mathrm{K}_{0}$ are the constants. In this paper, the thresholds of $\mathrm{K}_{2}$ and $\mathrm{K}_{0}$ and set at 0.1 for an unbalanced fault. The reason of choosing low threshold settings are that the combined information of negative and zero-sequence voltage magnitudes could improve the sensitivity of pickup criterion during a high-resistance earth fault [13].

If unbalanced fault condition is not satisfied then the substation will check for balanced fault criterion:

$$
V_{m 1} \leq K_{1} V_{n}
$$

$\mathrm{V}_{\mathrm{ml}}$ is the positive sequence voltage of $\mathrm{m}^{\text {th }}$ bus. $\mathrm{K}_{1}$ is a constant whose value is kept 0.6 in this paper. Higher threshold for the balanced fault is chosen in order to avoid frequent pickup of the WABP system under normal switching condition of the power system. If it is as high as 0.8 or 0.9 then even any load fluctuation also can generate trip signal and if it is as low as 0.1 or 0.2 also then in case of many faults, trip signal may not be generated[13]. So, a moderate value 0.6 is chosen.

Step 6: Compute absolute angle difference of all lines connected to bus or area $\mathrm{k}$.

Step 7: Obtain highest value line of Phase angle.

Step 8: The $\mathrm{j}^{\text {th }}$ line connected to area $\mathrm{k}$ is faulted line.

Step 9: Authentication if series capacitor compensation involved in the faulted line:

Check $g_{2 s}, g_{2 s}{ }^{1}, g_{2 R}$ all $\geq 0$

for an unbalanced fault.

Check $g_{1 s}, g_{1 s}{ }^{1}, g_{1 R}$ all $\geq 0$

for a balanced fault.

Step 10: Relaying Algorithm

Step 11: Stop 


\section{Case Studies}

A. Wscc-3 Machine-9 Bus System Applications

The proposed Wide Area Measurement Back up protection algorithm is tested for a WSCC 3-Machine-9 bus system(ref. Figure 1). Using EMTDC/PSCAD and MATLAB/ SIMULINK softwares simulations are carried out for different types of fault and even simultaneous faults in different branches of the system (both balanced and unbalanced faults). The data sampling rate is maintained $4 \mathrm{KHz}$ throughout.

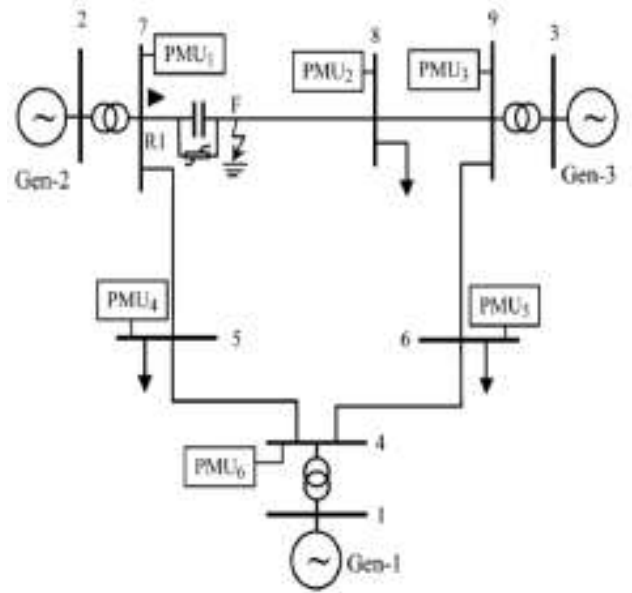

Figureure 1. Single Line Diagram of WSCC-3Machine-9bus With PMUs

Emperical formula of fault current

$$
I_{F i}=\frac{I_{s i}+I_{R i} \cos \left(h \gamma_{i} l_{i}\right)-\frac{V_{R i}}{Z_{c i}} \sin \left(h \gamma_{i} l_{i}\right)}{\cos \left(h \gamma_{i} l_{i} d\right)}
$$

Fault Voltage

$$
V_{F i}=V_{R i} \cos \left(\gamma_{i} l_{i}(1-d)\right)-Z_{c i} I_{R i} \sinh \left(\gamma_{i} l_{i}(1-d)\right)
$$

Fault impedance

$$
Z_{F i}=\frac{V_{F i}}{I_{F i}}
$$

Where, $I_{F i}=$ fault current at the $\mathrm{i}^{\text {th }}$ transmission line

$I_{s i}=$ Sending end current of the $\mathrm{i}^{\text {th }}$ transmission line, $I_{R i}=$ Receiving end current of the $\mathrm{i}^{\text {th }}$ transmission line, $V_{F i}=$ fault voltage at the $\mathrm{i}^{\text {th }}$ transmission line, $V_{R i}=$ Receiving end voltage of the $\mathrm{i}^{\text {th }}$ transmission line, $Z_{c i}=$ Characteristics impedance of the $\mathrm{i}^{\text {th }}$ transmission line, $Z_{F i}=$ fault impedance of the $\mathrm{i}^{\text {th }}$ transmission line, $\gamma_{i}=$ Propagation constant of the $\mathrm{i}^{\text {th }}$ transmission line, $l_{i}=$ length of the $\mathrm{i}^{\text {th }}$ transmission line, $d=$ fault distance.

\section{A.1 Case-i: LLG fault}

A double line-to-ground fault (ABG-type) is created at $0.34 \mathrm{~s}$ on line 5-7 at a distance of $30 \mathrm{~km}$ from bus-5 for $0.04 \mathrm{sec}$. A capacitor is used in Line 5-7 with $40 \%$ compensation. 
Saptarshi ROY, et al.

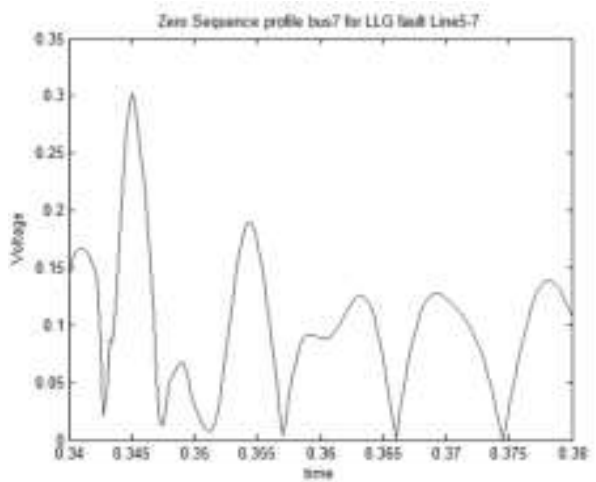

(a)

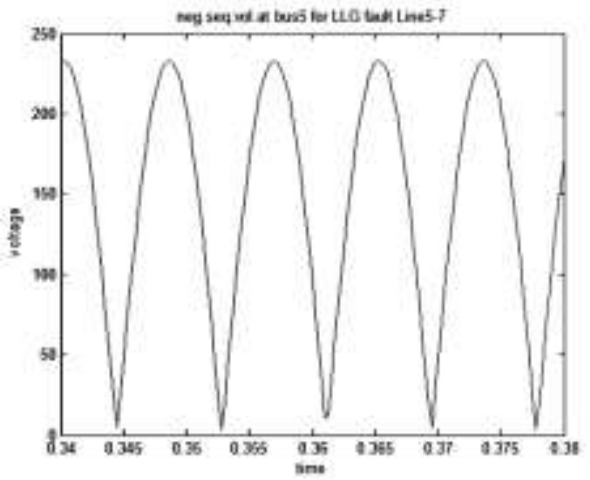

(b)

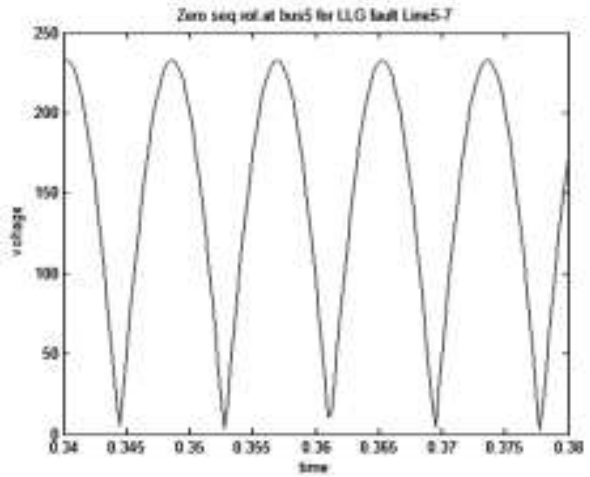

(c)

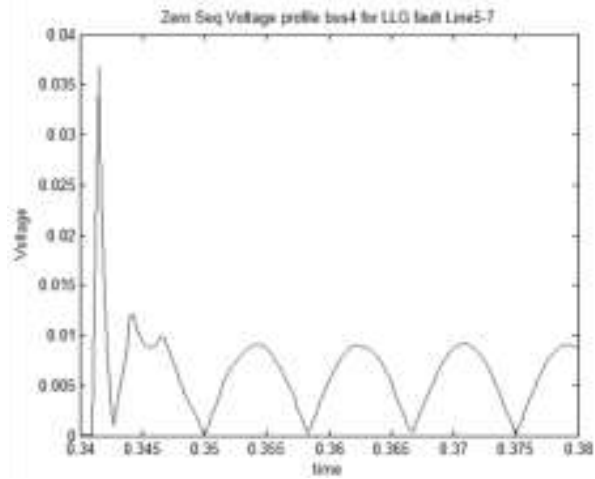

(d) 


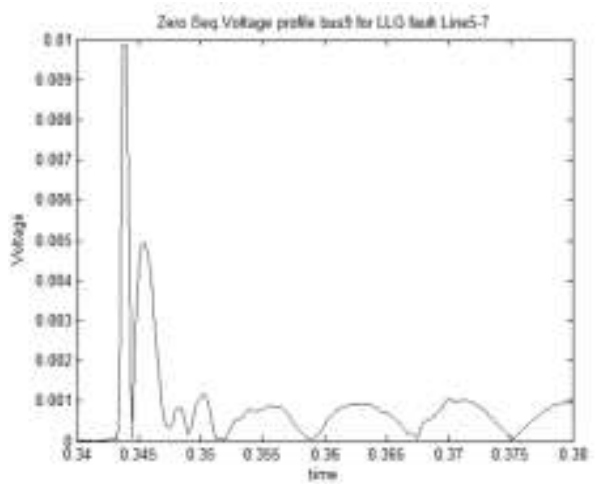

(e)

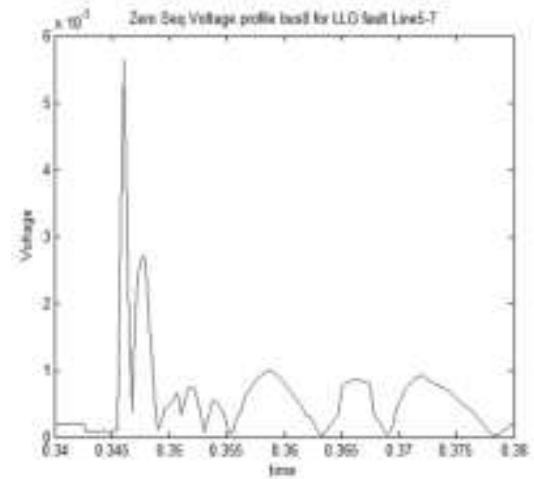

(f)

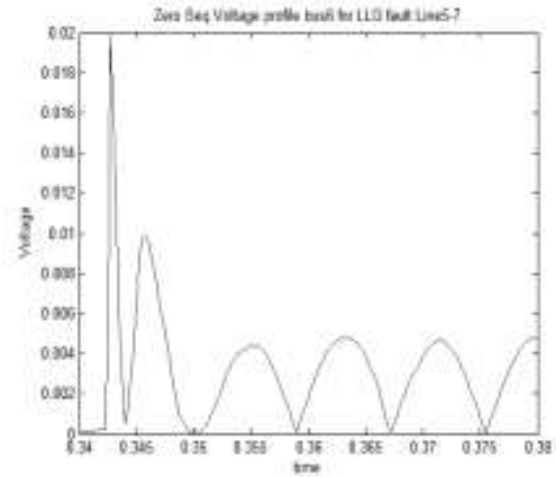

(g)

Figure 2(a). Zero Sequence Voltage Profile at bus 7 (b). Negative Sequence Voltage Profile at bus 5

(c). Zero Sequence Voltage Profile at bus 5 (d). Zero Sequence Voltage Profile at bus 4

(e). Zero Sequence Voltage Profile at bus 9 (f). Zero Sequence Voltage Profile at bus 8

The observation of the Figure no. 2(a), (b), (c), (d), (e), (f), (g) clearly shows it satisfies equation 4 , the pickup condition for unbalanced fault as:

$$
K_{2} V_{n}=K_{0} V_{n}=40 K V
$$

Bus 5 zero sequence voltage profile having maximum voltage magnitude among other buses in the network. However depending on source ,load and measurement errors in each substation some samples may deviate from the pickup criteria. So, the bus 5 data satisfies the 
criterion for an unbalanced fault and as bus 5 having maximum zero sequence magnitude, Bus5 is closest to the fault. All the voltages are expressed in $\mathrm{KV}$.

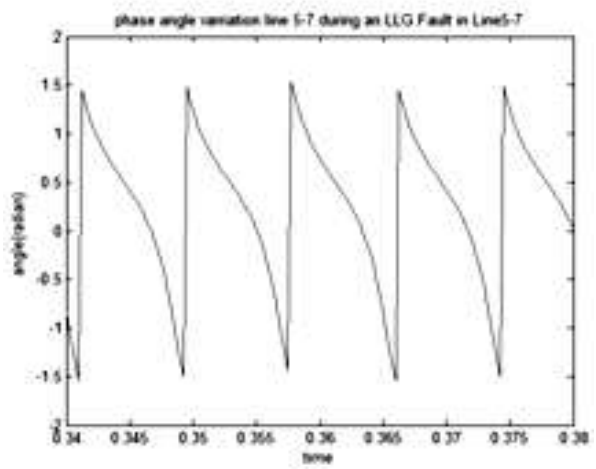

(a)

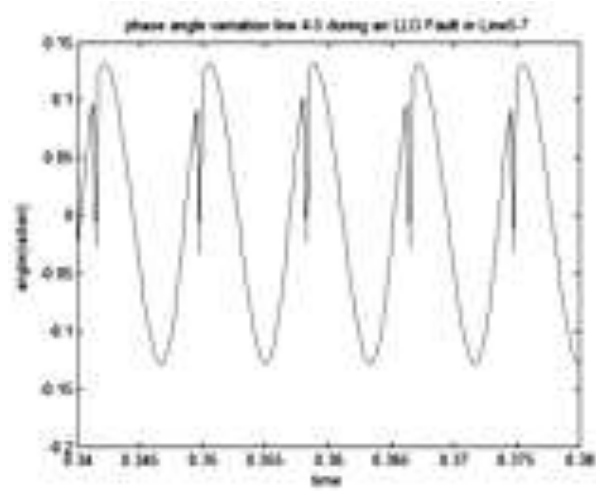

(b)

Figure 3(a) Phase variation of line 5-7 (b). Phase variation of line 4-5

Two lines are adjacent to bus 5, line 5-7 and line 4-5. The phase variations of those lines are shown in Figure 3( a) and Figure 3(b). The variations are expressed in radians. It is seen that the variations of the phase lies between $-\pi / 2$ to $+\pi / 2(-90$ degree to +90 degree $)$.

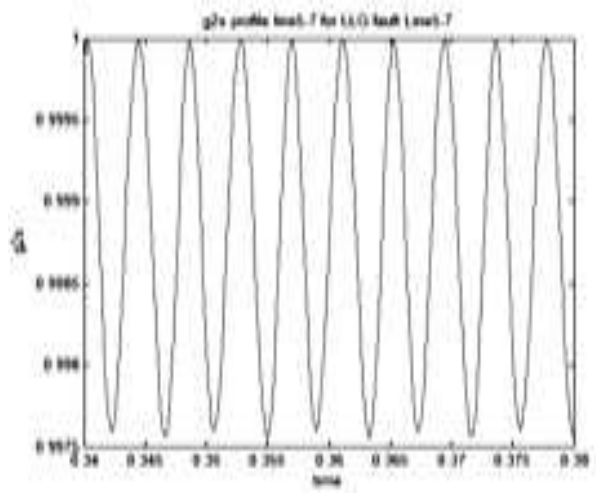

(a) 


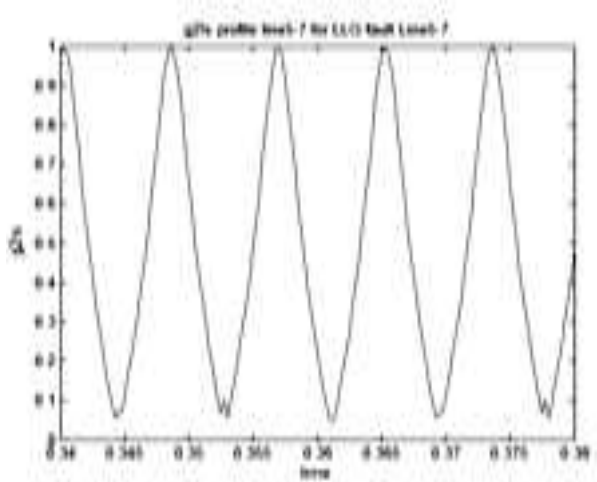

(b)

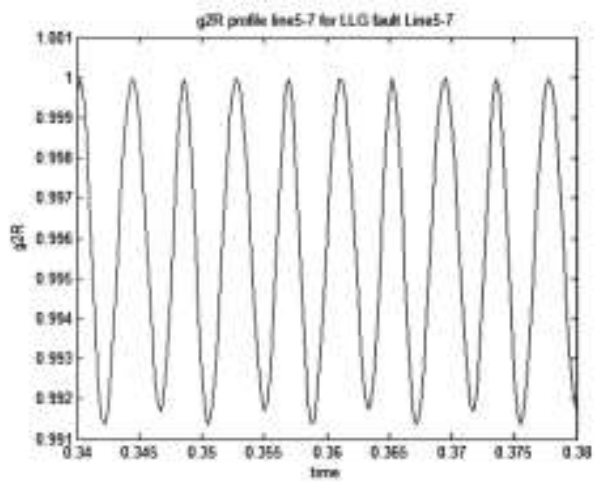

(c)

Figure 4(a) $g_{2 s}$ profile (b). $g_{2 s}$ profile (c). $g_{2 R}$ profile

From the Figure 3(a),3(b) and 4(a),4(b),4(c) it is clear that line 5-7 is satisfying equation (6) also, hence the criterion and authentication of an unbalanced fault. So, line 5-7 is the faulted line.

\section{A.2 Case-ii :LLLG Fault}

a LLLG fault is created at $0.34 \mathrm{~s}$ on line 5-7 at a distance of $30 \mathrm{~km}$ from bus-5 for 0.04 sec. After collecting all data, the following analysis has been done

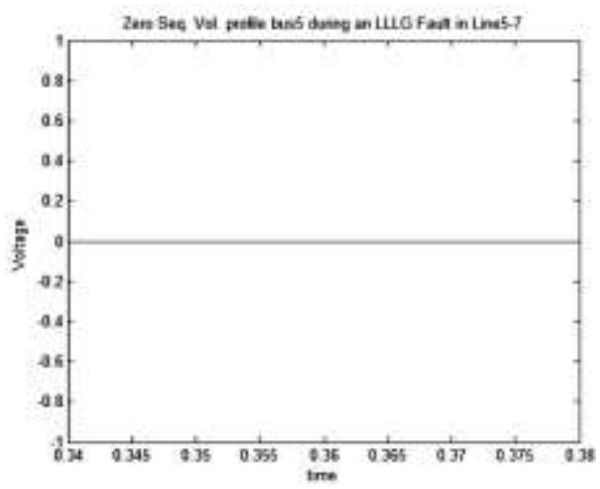

(a). 
Saptarshi ROY, et al.

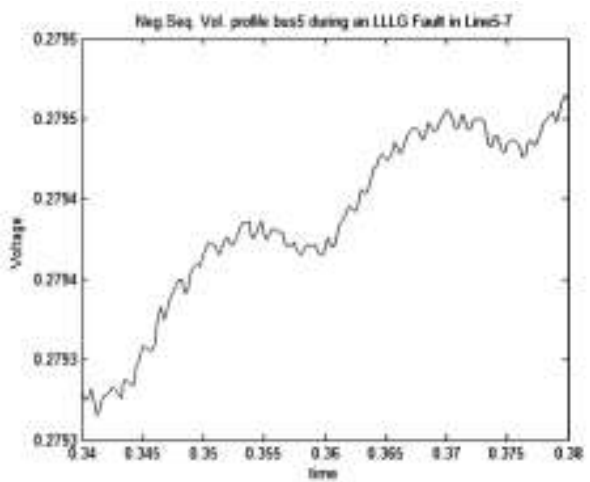

(b).

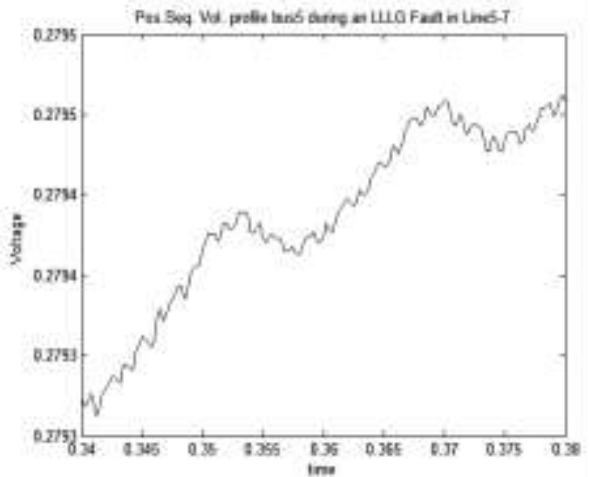

(c)

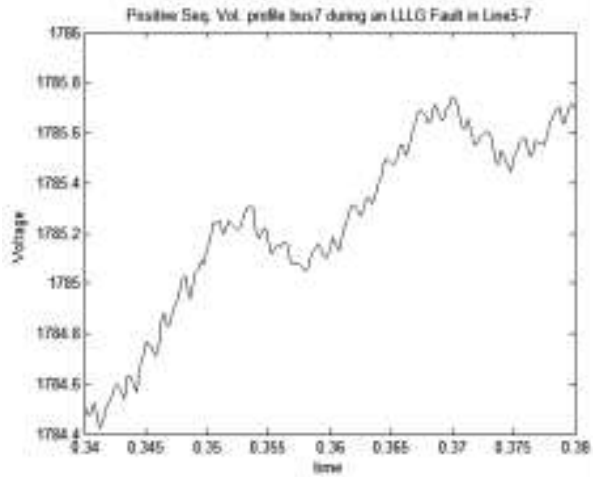

(d).

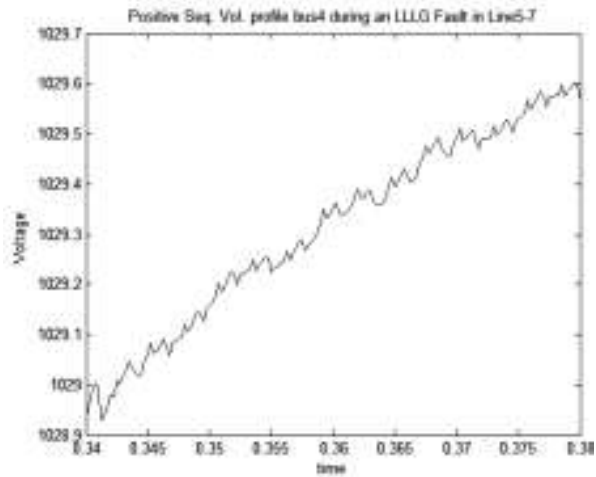

(e). 


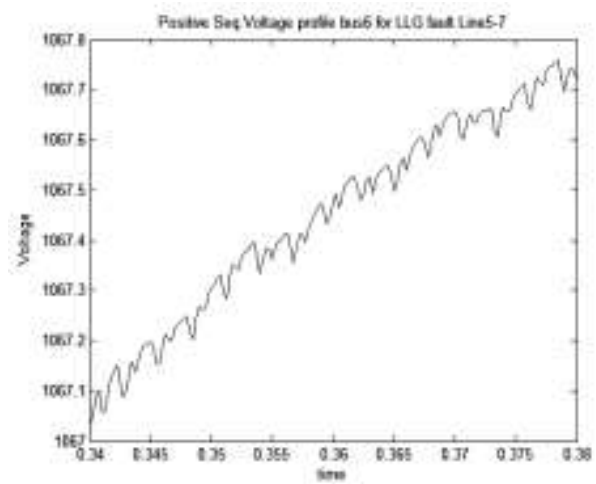

(f)

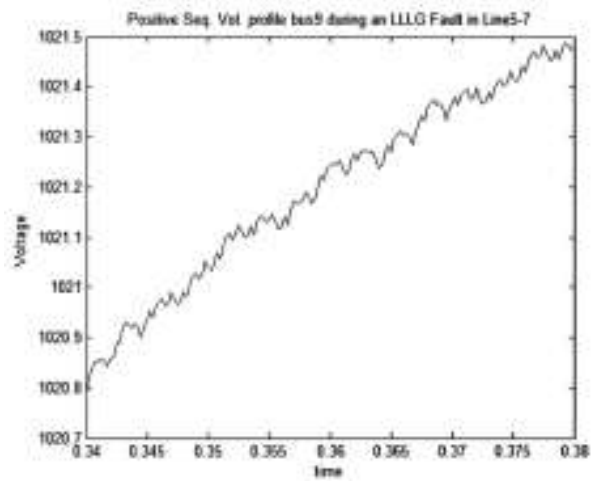

$(\mathrm{g})$.

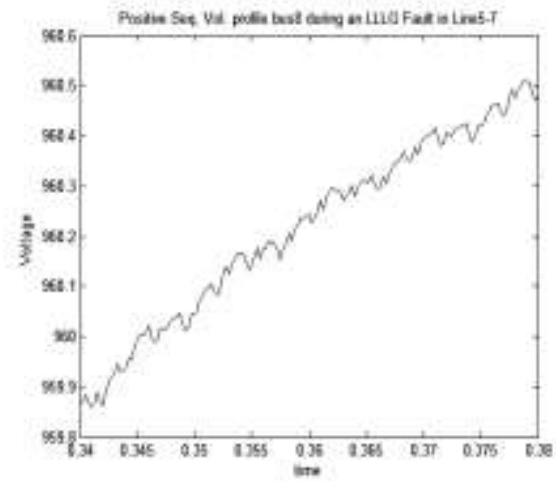

(h).

Figure 5(a) Zero Sequence Voltage Profile at bus 5 (b).Negative Sequence Voltage Profile at bus 5

(c). Positive Sequence Voltage Profile at bus 5 (d). Positive Sequence Voltage Profile at bus 7

(e) Positive Sequence Voltage Profile at bus 4 (f) Positive Sequence Voltage Profile at bus 6

(g) Positive Sequence Voltage Profile at bus 9 (h) Positive Sequence Voltage Profile at bus 8

All the units of voltage are expressed in KV here. Time is expressed in second. The observation of the Figure 5(a) to 5(h) clearly shows it does not satisfy equation (4), the pickup condition for unbalanced fault as $V_{m 2} \leq K_{2} V_{n} \quad \& \& V_{m 0} \leq K_{0} V_{n}$

$K_{2} V_{n}=K_{0} V_{n}=40 K V$

But it satisfies equation (5), the pickup criterion of a balanced fault as $K_{1} V_{n}=240 K V$ And minimum value of positive sequence voltage exist in bus 5 . So, bus 5 is considered as bus nearest to the fault. 
Saptarshi ROY, et al.

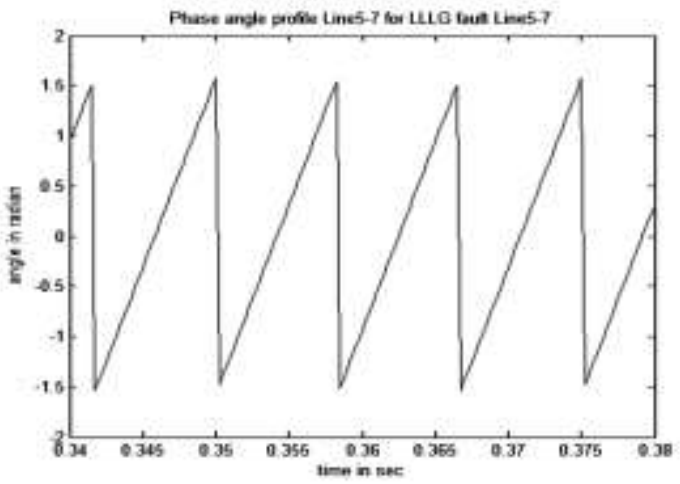

(a).

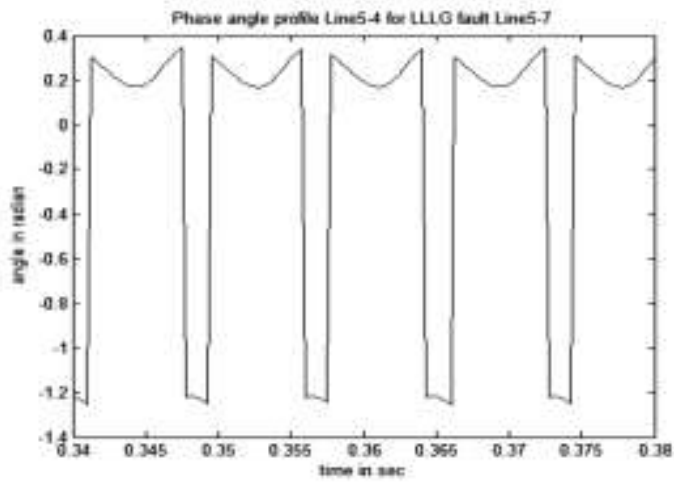

(b)

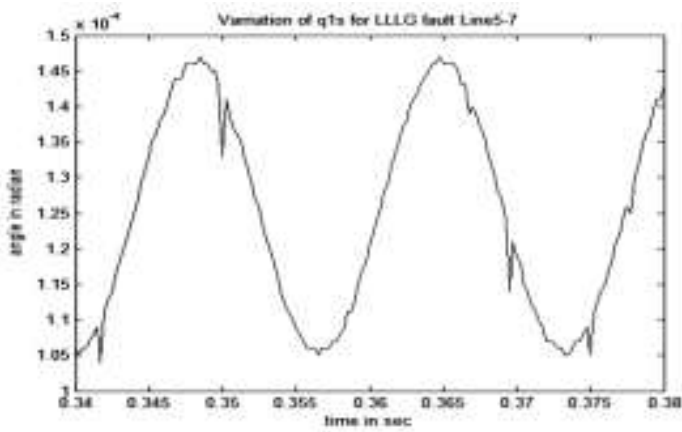

(c).

Figure 6(a). Phase Variation Line 5-7

(b). Phase Variation Line 4-5

(c). Variation of, $\varnothing_{1 \mathrm{~s}}$ for Line 5-7 


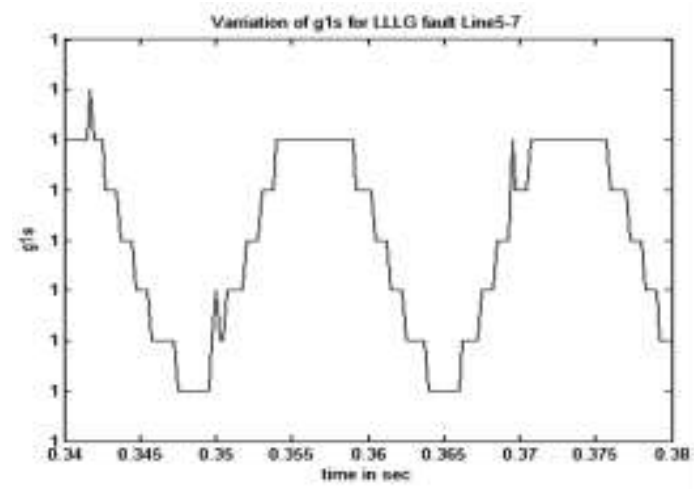

(a).

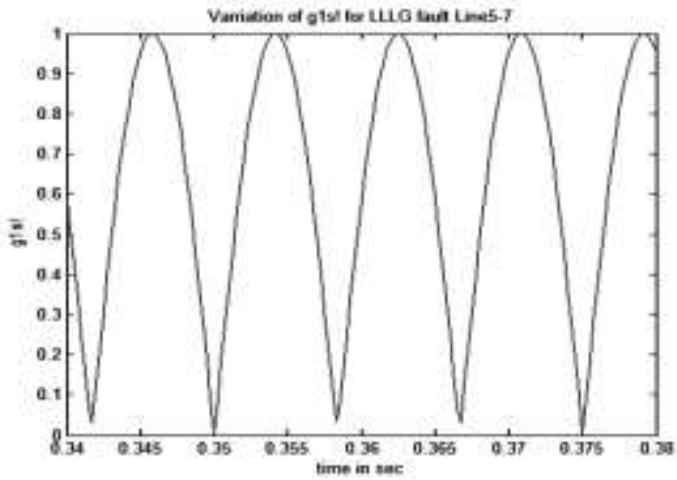

(b).

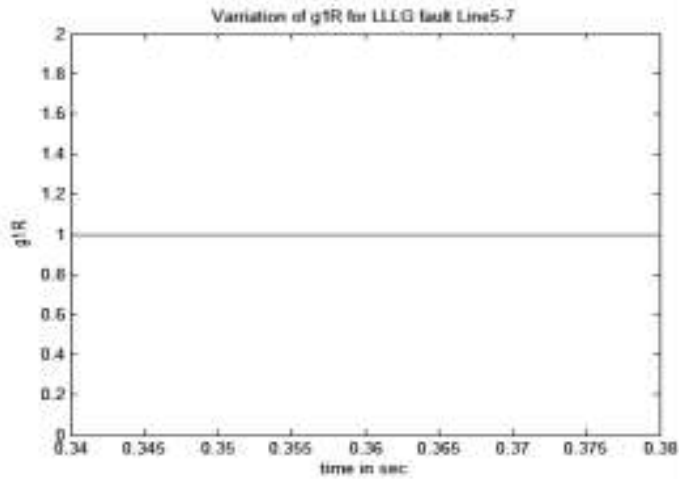

(c).

Figure 7(a). g $g_{1 s}$ profile during LLLG fault

(b). $\mathrm{g}_{1 \mathrm{~s}}$ ' profile during LLLG fault

(c). $\mathrm{g}_{1 \mathrm{R}}$ profile during LLLG fault

From the Figure 6(a), 6(b), 6(c) and 7(a), 7(b),7(c), it is clear that line 5-7 is satisfying equation (7), hence the criterion and authentication of an balanced fault. So, line 5-7 is the faulted line. 


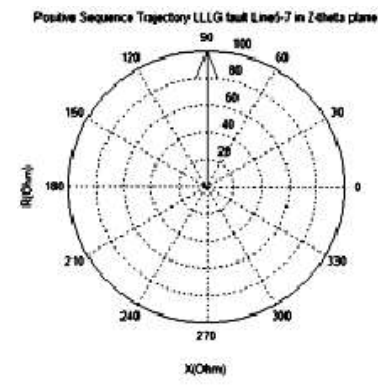

Figure 8. Positive Sequence Impedance Trajectory in Z-ø plane

The positive sequence impedance seen by the relay during the fault is plotted in the impedance plane(ref. Figure8). From the trajectory of the fault impedance, it can be concluded which zone the locus is confined and whether distance relay is going to generate any trip signal to circuit breaker or not and if there is any chance for evolving load encroachment problem or not.

\section{A.3 Case-iii: Simultaneous Faults}

Protection of power systems or occurrence of faults in a power network is not an isolated task $[14,15,16]$. It may happen simultaneously. So, now the new WABP algorithm is tested under the condition of occurrence of simultaneous faults across the power network. And here also it is found that it is having immunity to support simultaneous occurrence of faults phenomena.

\section{- Bus 5 With LLL and Bus 9 with LLG Fault}

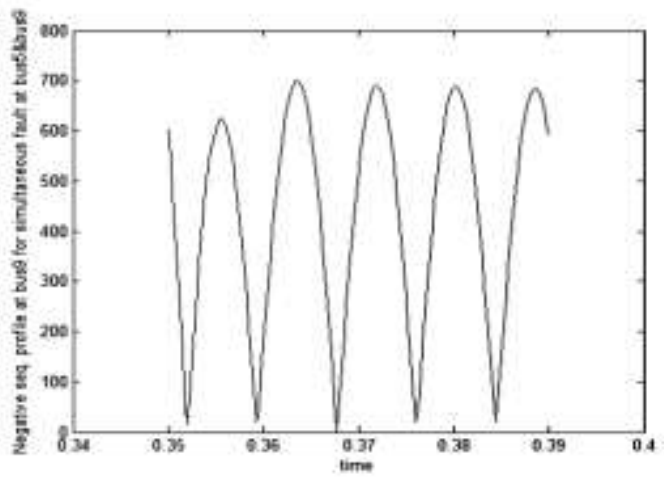

(a).

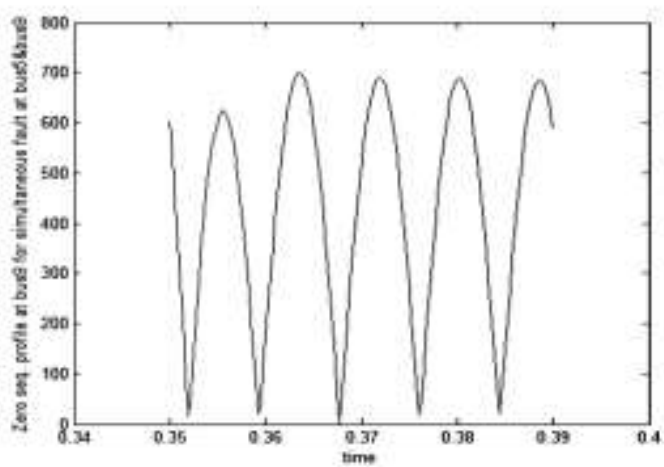

(b).

Figure 9 (a) Negative Sequence Profile at bus 9 (b). Zero Sequence Profile at bus 9 
Here also both the sequence voltage profiles will satisfy their individual fault pick up criterion (ref. Figure 9(a) and Figure 9(b)). However depending on source, load and measurement errors in each substation some samples may deviate from the pickup criteria.

- Bus 5, Bus 8, Bus 9 with balanced Fault.

Figure 10 (a) and 10(b) are showing the voltage profiles at bus 5

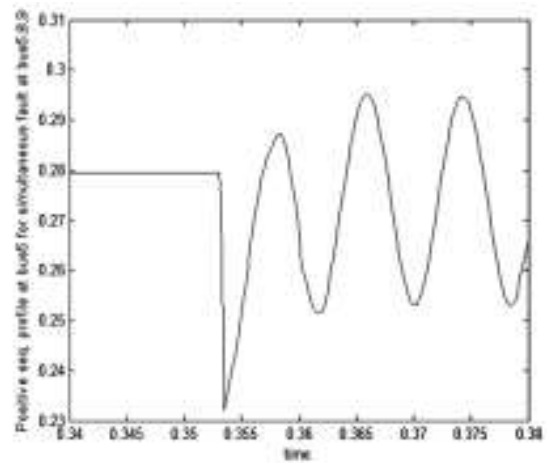

(a).

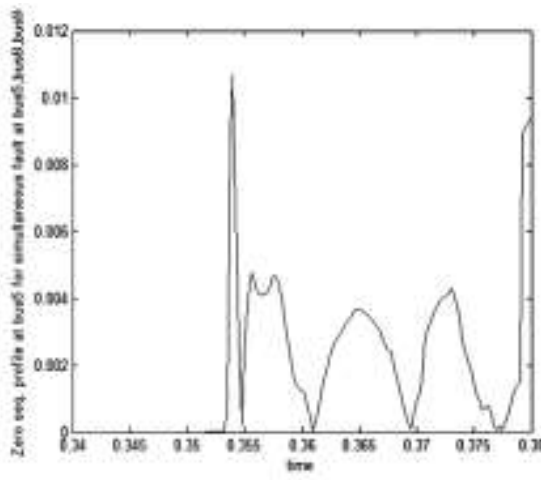

(b).

Figure 10(a). Zero Sequence Voltage bus 5 (b). Positive Sequence Voltage bus 5

During load encroachment and power swing conditions, the positive sequence impedance may enters zone 3 of relay which can cause undesired tripping of lines. But in those cases FLI criterion will not satisfy and thus such events will declare as a non-fault situation by the scheme. Thus WABP Scheme mitigates the problem raised during load encroachment and power swing conditions. So, this scheme is useful for Zone 3 protection support also.

A.4 Case-iv: Sources of error/ Limitation: Simultaneous faults at different Lengths of the same Line :

A-G fault is created at Line $5-7$ at $0.32 \mathrm{sec}$ for $0.04 \mathrm{sec}$ at $30 \mathrm{KM}$ distance from bus 5 and at the same time another fault is created on the same line and almost at the same distance (within $1 \mathrm{~km}$ )for $0.34 \mathrm{sec}$ for $0.04 \mathrm{sec}$ which is a 3 -phase fault. Now the fault voltage profile from 0.32 sec to $0.38 \mathrm{sec}$ for bus 5 is indicated as follows: 


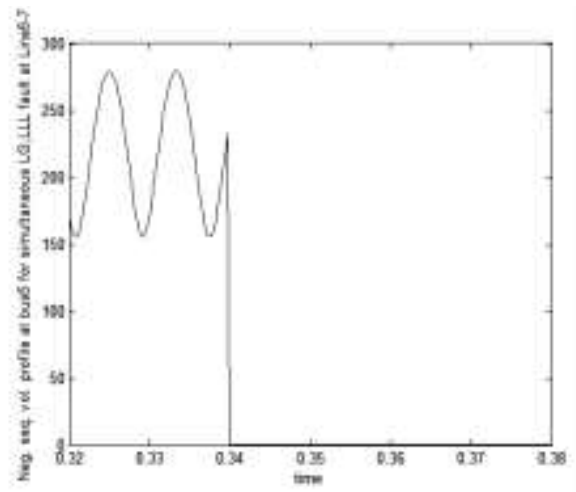

(a).

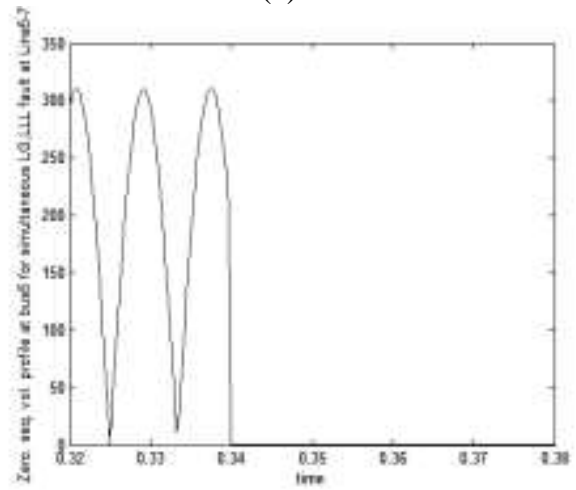

(b).

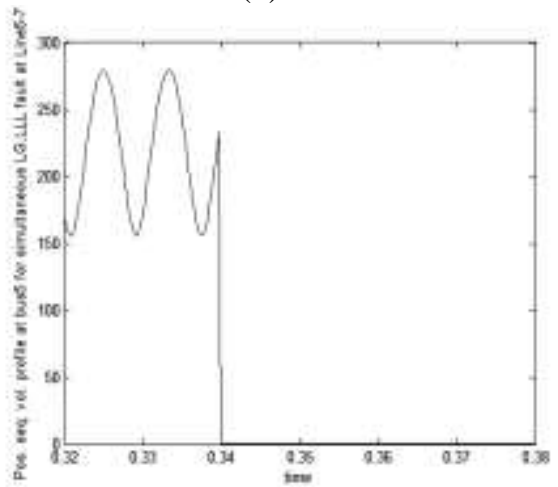

(c).

Figure 11(a) Negative Seq. voltage

(b). Zero Seq. Voltage

(c) Positive Seq. Voltage

Figure 11( a,b,c): Sequence voltage profiles at bus 5

From the above Figure no. 11(a), 11(b), 11(c) it is clear that result waveforms having two parts.

i) Up to $0.32-0.34 \mathrm{sec}$, it is obeying the pickup criterion of an unbalanced fault.

ii) $0.34-0.38 \mathrm{sec}$, the waveforms are obeying the pickup criterion for a balanced fault.

Theoretically, the wave should have three parts, $0.32-0.34 \mathrm{sec}$ unbalanced fault, $0.34-0.36 \mathrm{sec}$ both balanced and unbalance fault exist in the line and 0.36-0.38 sec balanced fault exist in the line. Here the circuit is obeying superposition theorem of network. As 3-phase fault is the most 
severe fault in the circuit, it nullifies the effect of an unbalanced fault and predominates. So, with this scheme if some balanced fault is indicating, it may contain some percentage of simultaneous unbalanced faults also, in the line as faults in power system is not an isolated issue. This scheme is showing unbalanced fault means the line contains unbalanced faults only but in case of balanced fault, the line may contain some percentage of unbalanced faults also.

So, Existence of Simultaneous faults in the same Line can be confirmed by the following logic:

i) Balanced + Unbalanced- Output Balanced

ii) Balanced + Balanced- Output Balanced

iii) Unbalanced + Balanced- Output Balanced

iv) Unbalanced + Unbalanced -Output Unbalanced

The above four postulates can be represented in a form of truth table as table 1

Table 1. Simultaneous fault logic

\begin{tabular}{|c|c|c|}
\hline Balanced & Unbalanced & $\begin{array}{c}\text { Output } \\
\text { Balanced }\end{array}$ \\
\hline High & $X$ & High \\
\hline Low & High & Low \\
\hline \multicolumn{3}{|c|}{$X$ - Indicates don't care condition. }
\end{tabular}

With the existing scheme, it is difficult to distinguish the Simultaneous faults in a same line. Moreover, depending on the source strength, demand of load and other errors in measurement and operation, some samples may deviate from their own pick up criterion sometimes[16,17,18,19].

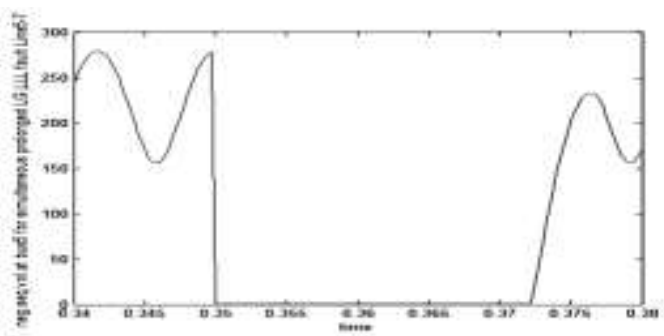

Figure 12. Negative Sequence Profile at bus5

Figure 12 is another case study, where an A-G fault is created at $0.34 \mathrm{sec}$ for $0.04 \mathrm{sec}$ on Line 5-7 at 30KM distance, at the same time another close in fault which is a 3-phase fault by nature is created on the same line for $0.02 \mathrm{sec}$. Same as previous case between $0.35-0.37 \mathrm{sec}$, the balanced fault predominates and suppressed the effect of unbalanced A-G fault and once the balanced fault is cleared ,between $0.37-0.38 \mathrm{sec}$, the effect of unbalanced fault is again seen. Thus output is a composite Figure in nature. So, in the presence of a balanced fault, the effect of unbalanced fault cannot be distinguished as LLL fault predominates with respect to its degree of severity than LG fault.

\section{B. Application on An IEEE-14 Bus System}

The method discussed above is also tested on an IEEE-14 bus system to prove its effectiveness. The test system (ref. Figure 13) is constructed by using PSCAD software. Different cases are simulated on this test system to show the effectiveness of the proposed method. 
Saptarshi ROY, et al.

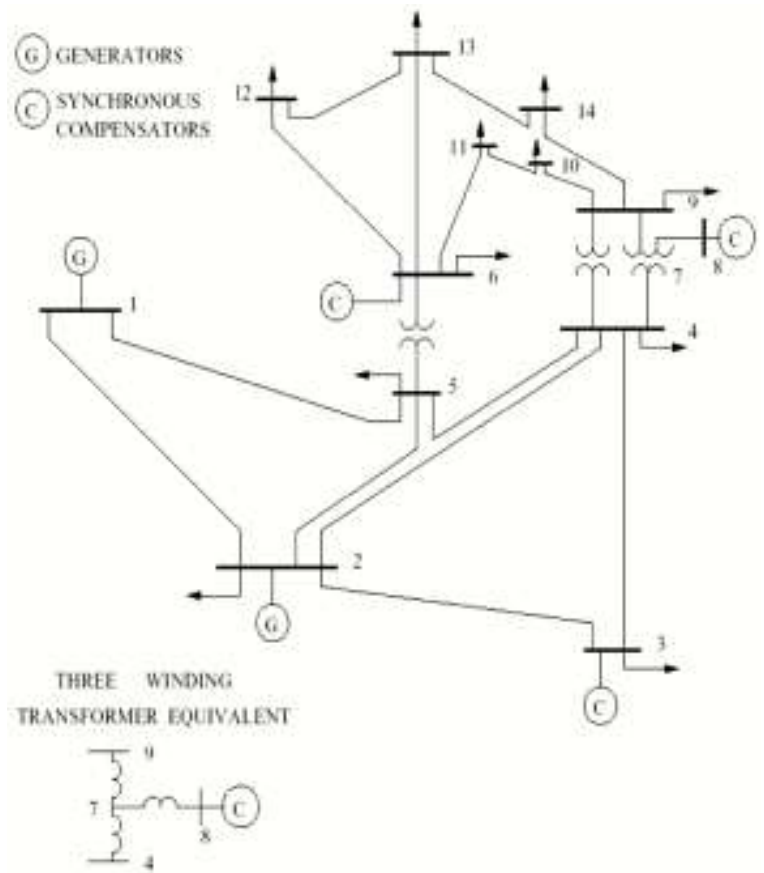

Figure 13. Single Line Diagram of an IEEE-14 bus test system

B.1 Case-i: LG fault

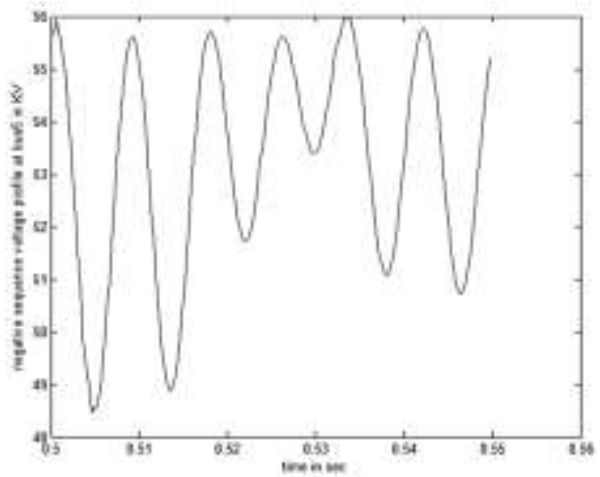

(a).

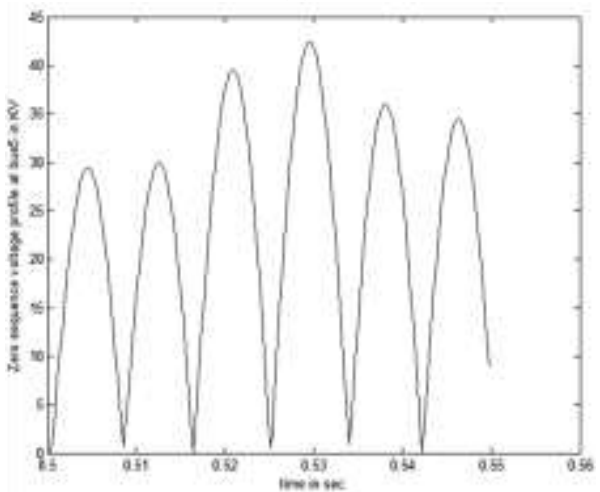

(b). 


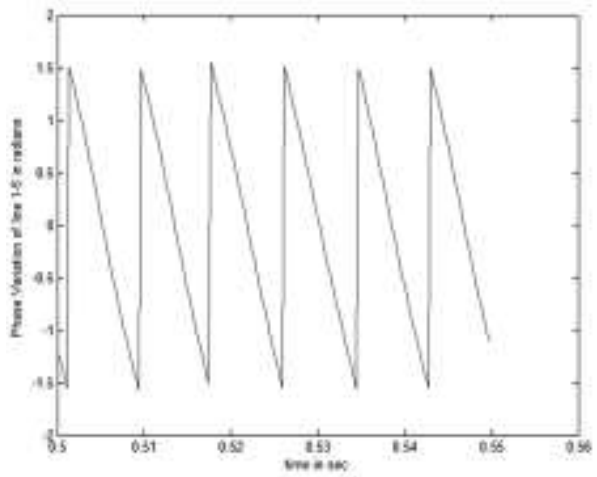

(c).

Figure 14(a,b,c). Sequence Voltage profiles at bus 5 and phase angle variation in line 1-5

A Phase A-G fault is created at line $1-5$ at $0.5 \mathrm{sec}$ for $0.05 \mathrm{sec}$ duration at a distance $50 \mathrm{Km}$ from bus 1 (33.87 $\mathrm{Km}$ from bus 5). A capacitor with $40 \%$ compensation is used in line 1-5. The bus nominal voltages are $138 \mathrm{KV}$. From the analysis of its sequence component voltages and phase angles it is found that bus5 is satisfying the bus closest to the fault and unbalanced fault pick up criteria as $\mathrm{K}_{2} \mathrm{~V}_{\mathrm{n}}=\mathrm{K}_{0} \mathrm{~V}_{\mathrm{n}}=13.8 \mathrm{KV}$. Bus 5 is connected with line 1-5, line 4-5 and line 5-6. Among them line 1-5 has highest value of phase angle. So, line 1-5 is the faulted line. The sequence voltages and phase angle variations are shown in Figure 14 (a,b,c). All g index values are also found to be positive. So, it is satisfying the authentication of unbalanced fault also.

\section{B.2 Case-ii :LLLG Fault}

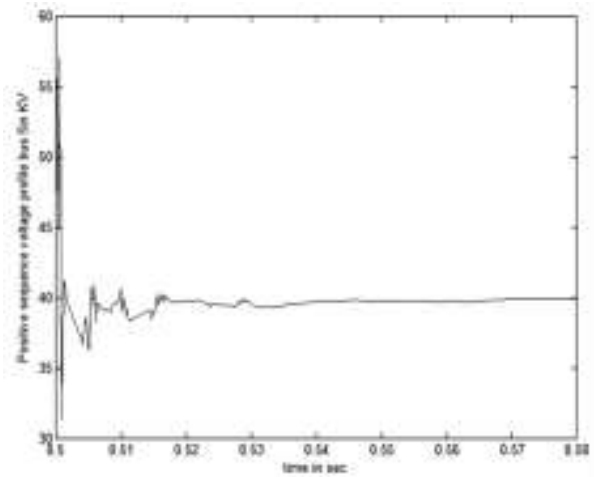

(a). Positive Sequence Voltage profile at bus 5

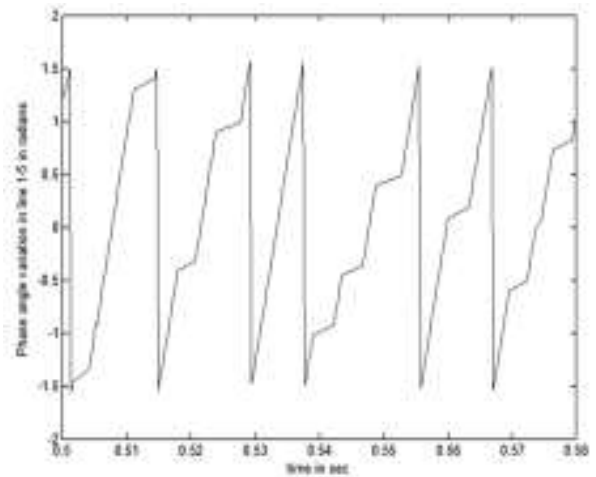

(b). Phase angle variation of line 1-5

Figure 15(a,b). Sequence Voltage profile at bus 5 and phase angle variation in line 1-5 
A LLLG fault is created at line $1-5$ at $0.5 \mathrm{sec}$ for $0.05 \mathrm{sec}$ duration at a distance $50 \mathrm{Km}$ from bus 1 (33.87 $\mathrm{Km}$ from bus 5). A capacitor with $40 \%$ compensation is used in line 1-5. The bus nominal voltages are $138 \mathrm{KV}$. From the analysis of its sequence component voltages and phase angles, it is found that bus5 is satisfying the bus closest to the fault and balanced fault pick up criteria as $\mathrm{K}_{1} \mathrm{~V}_{\mathrm{n}}=82.8 \mathrm{KV}$. Bus 5 is connected with line 1-5, line 4-5 and line 5-6. Among the line 1-5 has highest value of phase angle. So, line 1-5 is the faulted line. The sequence voltage and phase angle variations are shown in Figure 15(a,b). All g index values are also found to be positive. So, it is satisfying the authentication of balanced fault also.

\section{B.3 Case-iii: Simultaneous Faults}

- Line 1-5 with LLLG fault and Line 5-4 with LG fault:

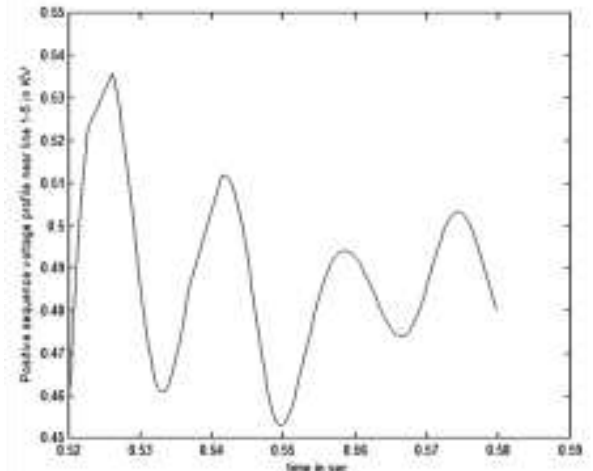

(a). Positive sequence voltage profile at line 1-5

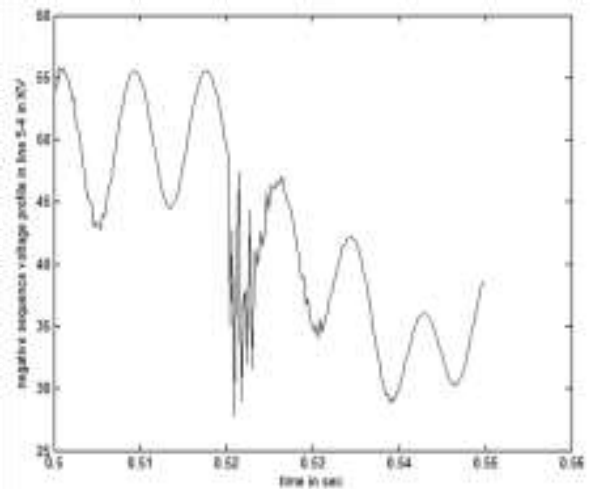

(b). Negative sequence voltage profile at line 5-4

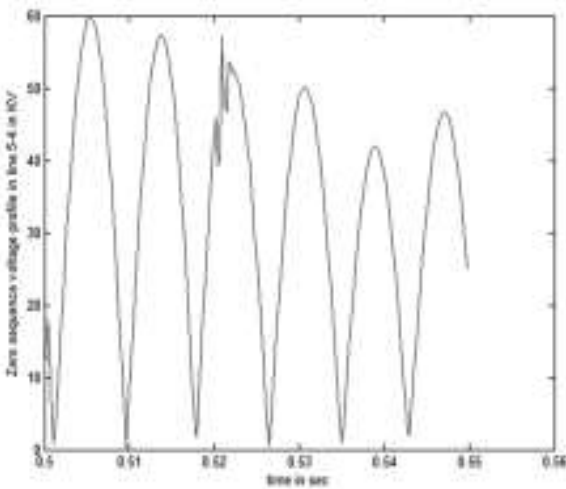

(c). Zero sequence voltage profile at line 5-4 


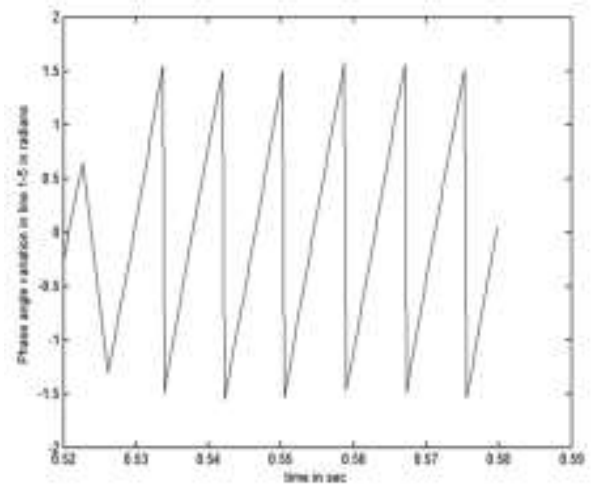

(d). Phase angle variation of line 5-4

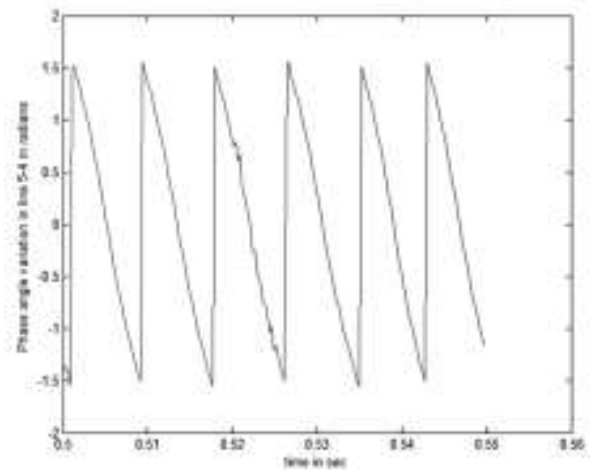

(e). Phase angle variation of line 1-5

Figure 16(a,b,c,d,e). Sequence Voltage profiles and phase angle variations

A LLLG fault is created at $50 \mathrm{Km}$ distance from bus 5 at line $1-5$ at $0.52 \mathrm{sec}$ for $0.06 \mathrm{sec}$ duration and a LG close in fault is created at line 5-4 at $0.5 \mathrm{sec}$ for $0.05 \mathrm{sec}$ duration. From the sequence voltages and phase angle variation analysis, it is found that each line will satisfy their own individual fault pick up criteria. The sequence voltage profiles and phase angle variations are shown in Figure 16(a,b,c,d,e).

- Simultaneous faults at different Lengths of the same Line:

An AG fault is created at line 1-5 in close in distance at a time 0.5 for $0.05 \mathrm{sec}$ duration and a LLLG fault is created in the same line at a distance $20 \mathrm{Km}$ from bus 1 at $0.52 \mathrm{sec}$ for 0.06 sec duration. The composite fault voltage sequence waveforms are shown in Figure 17(a,b).

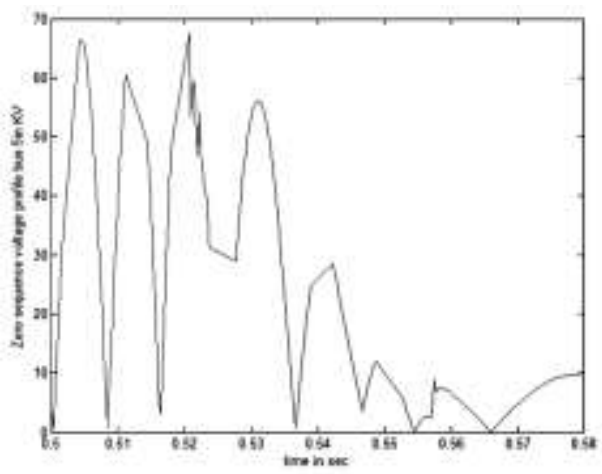

(a). Zero sequence voltage profile at line 1-5 


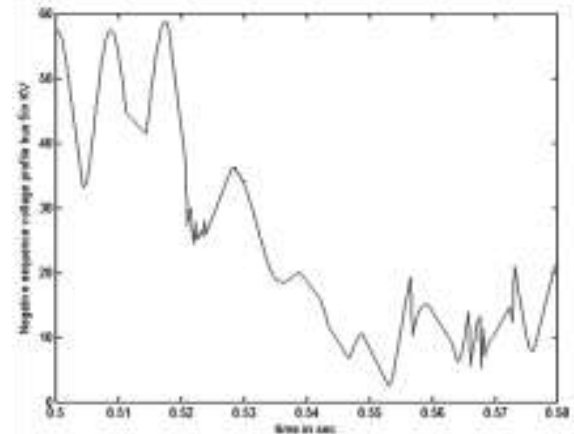

(b). Negative sequence voltage profile at line 1-5

Figure 17(a,b). Sequence Voltage profiles in line 1-5 when simultaneous AG and LLLG fault exist in the line

From the composite waveform it is clear that from $0.5-0.52 \mathrm{sec}$ unbalanced fault pick up criterion is satisfying and from $0.52-0.58 \mathrm{sec}$, balanced fault pick up criterion is gradually predominating. The only difference with 9 bus case studies is, in case of 9 bus, whenever there exist a balanced and unbalanced fault in the system, the balanced fault starts to predominate immediately but in case of IEEE 14 bus system balanced fault starts to predominate gradually. The cause of this change can be explained as the influence of the length or size of the system which introduces a delay in the predomination of balanced fault. The delay can be further increased if the methodology is tested for more higher and larger test systems.

\section{Discussions}

\section{A. Reduction of PMUS}

We need voltage data of the whole system for analysis of the methodology. But placing PMUs in each bus to capture data is a costly affair specially in case of a larger system. Here, an Integer Linear Programming (ILP) is used to solve the PMU placement problem. The results obtained are presented in the Table II shown below. Our objective is to make the system complete observable with minimum number of PMUs. The minimum number of PMUs to make the system complete observable is roughly $1 / 3$ rd of the total number of buses exist in the system except zero injection buses[15,20].

Table 2: Complete observability under normal operating conditions in test systems

\begin{tabular}{|l|c|c|}
\hline System & Location of PMUs in bus no. & Number of PMUs \\
\hline WSCC-3-machine-9bus & $4,6,8$ & 3 \\
\hline IEEE 14 bus & $2,6,8,9$ & 4 \\
\hline
\end{tabular}

\section{B. Stability of the method}

This method will work fine even in the transient conditions of the network. It is not depending on fault level. The method is totally depending on extracted voltage and current samples. So, the method is stable and not going to affect the stability of the system.

\section{Conclusion}

A Novel WABP scheme based on synchronized phasor measurements is proposed in this paper. The sequence components of voltage, phase angles and the sign of cosine of the angle between voltage and current at both ends of a line is utilized to identify The faulted area and faulted branch. Simulation results for the nine-bus and IEEE 14bus power system show that the method performs correctly during several faults in systems, interconnected systems and simultaneous faults. Apart from the simple setting principle, the scheme has the ability to 
distinguish the fault from load encroachment and power swing and can mitigate the short comings of the conventional backup protection scheme. It is helpful to prevent blackouts. Thus with the context of now a today's backup protection schemes, the scheme described here is commendable.

\section{APPENDIX-A}

System data for 3-machine 9-bus conFigureuration:

Gererators

Gen-1: 600 MVA,22KV,50HZ

Gen-2: 465 MVA,22KV,50HZ

Gen-3: 310

MVA,22KV,50HZ

Transformers

T1: 600 MVA,22/400KV,50HZ,T2: 465 MVA,22/400KV,50HZ,D/Y $\quad$ T3: 310 MVA,22/400KV,50HZ,D/Y

Transmission line:

Length of line $7-8=320 \mathrm{Km} \quad$ line $8-9=400 \mathrm{Km} \quad$ line $7-5=310 \mathrm{Km} \quad$ line $5-4=350 \mathrm{Km}$ line 6 $4=350 \mathrm{Km}$ line $6-9=300 \mathrm{~km}$.

Loads

Load A=300MW+j100MVAr. Load B=200MW+j75MVAr. Load C=150MW+j75MVAr.

Other parameter used are same as used in Reference [11] and IEEE 14 bus test system data is obtained from Reference [21]

\section{References}

[1]. S.Horowitz and A. G.Phadke, "Third zone revisited", IEEE Transactions on Power Delivery, ,vol. 21, no. 1, pp. 23-29, Jan.2006.

[2]. J. D. Ree,V. Centeno,J. S. Thorp, and A. G. Phadke, "Synchronized phasor measurement applications in Power systems," IEEE Transactions on Smart Grid, vol. 1, no. 1, pp. 20-27, June 2010.

[3]. A. G. Phadke and J. S. Thorp, Synchronized Phasor Measurements and Their Applications. New York: Springer, 2008.

[4]. M. M. Eissa, M. E. Masoud, and M.M.M. Elanwar, "A novel backup wide area protection technique for power transmission grids using phasor measurement unit," IEEE Transactions on Power Delivery, vol. 25, no. 1, pp. 270-278 , Jan. 2010.

[5]. P. V. Navalkar and S. A. Soman, "Secure remote backup protection of transmission lines using synchrophasors, "IEEE Transactions on Power Delivery, vol. 26, no. 1, pp. 87-96, Jan. 2011.

[6]. H. Lin, S. Sambamoorthy, S. Shukla, J. Thorp, and L Mili, "Ad-hoc vs. supervisory wide area backup relay protection validated on power/network co-simulation platform," presented at the 17th Power System Computation Conference, Stockholm, Sweden, Aug. 22-26, 2011.

[7]. J. Ma, J. Li, J. S. Thorp, A. J. Arana, Q. Yang, and A. G. Phadke, "A fault steady state component-based wide area backup protection algorithm," IEEE Transactions on Smart Grid., vol. 2, no. 3, pp. 468-475, Sep.2011.

[8]. Z.He, Z. Zhang,W. Chen,O. P.Malik, and X. Yin, "Wide-area backup protection algorithm based on fault component voltage distribution," IEEE Transactions on Power Delivery, vol. 26, no. 4, pp. 2752-2760, Oct. 2011.

[9]. B. Kasztenny, "Distance protection of series-compensated lines problems and solutions," presented at the 28th Annual Western Protection Relay Conference, Spokane, WA, USA, Oct. 22-25, 2001.

[10]. D. Novosel, A. G. Phadke,M.M. Saha, and S. Lindahl, "Problems and solutions for microprocessor protection of series compensated lines" , Proceedings of Conference on Development on Power System. Protection, 1997, pp. 18-23. 
[11]. P.K Nayak, A.K Pradhan, and P. Bajpai, "A Fault Detection Technique for the SeriesCompensated Line During Power Swing”, IEEE Transactions on Power Delivery, vol. 28, no. 2, April 2013,pp.714-722.

[12]. S.N.Muneswar, R.Hasabe, D.Shelar, P.Kose, "A New Adaptive PMU based Protection Scheme for Interconnected Transmission Network System”, International conference on Circuit, Power and Computing Technologies, 2014.

[13].P.K Nayak, A.K Pradhan, and P.Bajpai, "Wide-Area Measurement-Based Backup Protection for Power Network with Series Compensation", IEEE Transactions on Power Delivery, vol. 29, no. 4, August 2014, pp.1970-1977.

[14]. A.K.Pradhan, P.Jena," Directional relaying in the Presence of a thyristor-controlled series capacitor", PES General Meeting, IEEE, 27-31 July, 2014.

[15]. T.Routtenberg, Yao Xie, R.M.Willett, Lang Tong," PMU Based Detection of Imbalance in Three-Phase Power Systems ”, IEEE Transactions on Power Systems ,Vol. 30, no. 4, July 2015,pp.1966-1976.

[16]. Ali.H.Al Mohammed, M.A.Abido, "A Fully Adaptive PMU Based Fault Location Algorithm for Series compensated Lines“, IEEE Transactions on Power Systems ,Vol.29, no.5, September 2014, pp.2129-2137.

[17]. I.Kamwa, S.R.Samantaray, G. Joos, "Wide Frequency Range Adaptive Phasor and Frequency PMU Algorithms", IEEE Transactions on Smart Grid ,Vol. 5, no.2, March2014, pp.569-579.

[18]. P.Kundu, A.K.Pradhan, "Online identification of protection element failure using wide area measurements", IET Generation, Transmission and Distribution, 2015, Vol. 9, Issue 2, pp 115-123.

[19]. W.Rebizant, J.Szafran and A.Wiszniewski, Digital signal processing in power system protection and control, Springer, Poland,2011.

[20]. Emily R Fernandes et al. ," Application of a phasor-only state estimator to a large power system using real pmu data ", IEEE Transactions on Power System, Vol.32, No.1, January 2017, pp.411-420.

[21]. Power flow data for IEEE 14 bus test case. http://www.ece.ubc.ca/ hameda/download_files/case14.m

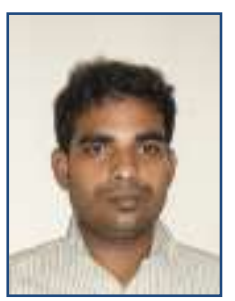

Saptarshi ROY, Received the B.E degree in Electrical Engineering from Jadavpur University, West Bengal, India in 2009. Received M.Tech degree from NIT Warangal in 2014. Currently he is pursuing $\mathrm{PhD}$ in Electrical Engineering in the department of Electrical Engineering, National Institute of Technology, Warangal, India. His areas of interest are power system protection, Phasor Measurement Unit applications in power systems, Synchrophasors applications in power systems.

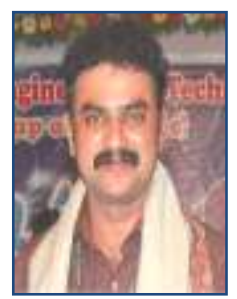

Suresh Babu PERLI, Currently he is working as an Assistant Professor in Department of Electrical Engineering, National Institute of Technology, Warangal. His areas of interest are Power System Protection with digital multifunction relays, Development of Adaptive protection schemes and Digital filtering algorithms. 


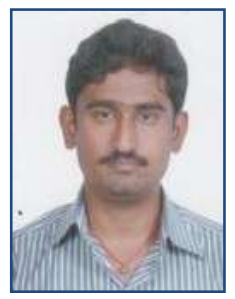

N V Phanendra BABU, He is currently doing Research in the Department of Electrical Engineering, National Institute of Technology Warangal, India. His areas of interest are Optimal PMU Placement, Wide-Area protection.

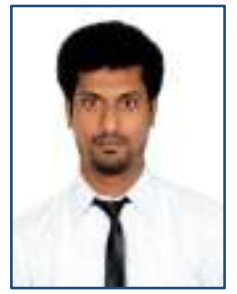

Abhishek KUMAR, He received B.E degree in Electrical Engineering from Shree Vaishnav Institute of Technology and Science, Indore in 2014. Currently he is pursuing M.Tech in Power Systems Engineering in the department of Electrical Engineering, National Institute of Technology, Warangal, India. His areas of interest are adaptive relaying, digital filtering algorithms and fault location algorithms. 